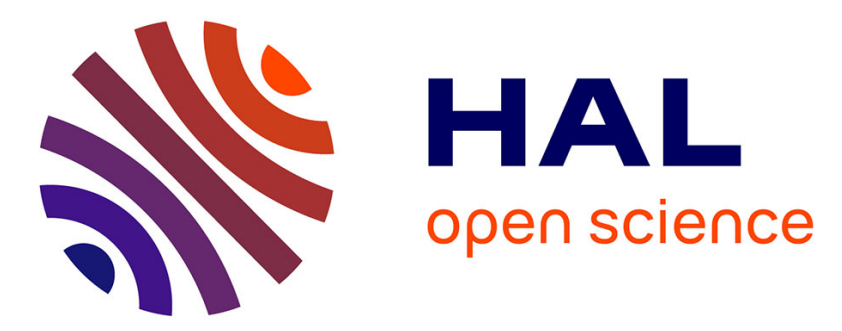

\title{
Barrier properties of poly(lactic acid) and its morphological changes induced by aroma compound sorption
}

Gael Colomines, Violette Ducruet, Cecile Courgneau, Alain Guinault, Sandra Domenek

\section{To cite this version:}

Gael Colomines, Violette Ducruet, Cecile Courgneau, Alain Guinault, Sandra Domenek. Barrier properties of poly(lactic acid) and its morphological changes induced by aroma compound sorption. Polymer international, 2010, 59 (6), pp.818-826. 10.1002/pi.2793 . hal-01173786

\section{HAL Id: hal-01173786 \\ https://hal.science/hal-01173786}

Submitted on 5 Dec 2017

HAL is a multi-disciplinary open access archive for the deposit and dissemination of scientific research documents, whether they are published or not. The documents may come from teaching and research institutions in France or abroad, or from public or private research centers.
L'archive ouverte pluridisciplinaire HAL, est destinée au dépôt et à la diffusion de documents scientifiques de niveau recherche, publiés ou non, émanant des établissements d'enseignement et de recherche français ou étrangers, des laboratoires publics ou privés. 


\title{
Barrier properties of poly(lactic acid) and its morphological changes induced by aroma compound sorption
}

\author{
Gael Colomines, ${ }^{\text {a }}$ Violette Ducruet, ${ }^{\text {b }}$ Cécile Courgneau, ${ }^{\text {b }}$ Alain Guinault ${ }^{\mathrm{a}}$ \\ and Sandra Domenek ${ }^{\text {b* }}$
}

\begin{abstract}
The barrier properties of poly(lactic acid) (PLA) play a key role in food packaging applications. For their optimization, the influence of crystallinity on the barrier properties of PLA and the interaction of PLA with the aroma compound ethyl acetate were investigated. PLA film samples with various crystallinities were fabricated by flat die extrusion and thermocompression and compared to PLA Biophan ${ }^{\mathrm{TM}}$. The degree of crystallinity had no effect on the oxygen permeability. However, an increase of crystallinity caused a decrease in ethyl acetate sorption. The sorption isotherm of ethyl acetate obtained using microgravimetry showed a steep increase with increasing aroma activity, a form which is consistent with a plasticization effect. This behaviour was verified using differential scanning calorimetry and dynamic mechanical analysis. Sorption caused a marked decrease in the glass transition temperature well below room temperature to approximately $0{ }^{\circ} \mathrm{C}$. Furthermore, PLA underwent a solvent-induced crystallization when equilibrated in ethyl acetate atmosphere at an activity of 0.5 . The results obtained show the importance of considering possible interactions between polymer and foodstuff during the optimization step of polymeric materials for food packaging applications.
\end{abstract}

Keywords: poly(lactic acid); barrier properties; thermomechanical properties; glass transition; food packaging

\section{INTRODUCTION}

The past few years, marked by the paradigm of sustainable development, have brought about a renewed interest in biodegradable polymers originating from renewable resources. The most important market for those novel polymers will be the packaging sector, within which food packaging represents approximately $65 \%$ by volume. Among bio-source-based polymers emerging on the food market, the semi-crystalline polyester poly(lactic acid) (PLA) is one of the most applied because of its relatively low cost and ease of processing.

Initially used in biomedical applications ${ }^{1}$ such as self-degrading suture materials, PLA has promising properties and it is approved for food contact. ${ }^{2}$ It is well adapted for the packaging of fresh products with short shelf-life. In order to increase the use of PLA packaging volume it is also important to offer functional packaging for products with longer shelf-life. Important functionalities of packaging are not only to ensure food safety, but also to guarantee the organoleptic quality of the packed product during its shelflife. Therefore, the barrier properties of the packaging polymer against the transfer of small molecules, such as $\mathrm{O}_{2}, \mathrm{CO}_{2}$ or $\mathrm{H}_{2} \mathrm{O}$, are important. In particular, oxygen is an excellent oxidizing agent of lipids $s^{3}$ which can cause deterioration of product quality. Moreover, barrier properties against larger volatile molecules, such as aroma compounds, need to be assessed since the transfer of these compounds into the polymer could cause a modification of the aroma formulation of the packaged food leading to a deterioration of its quality. ${ }^{4-7}$
Barrier properties of semi-crystalline polymers are affected by the crystallinity of the polymer, since crystalline zones are excluded volumes where molecules cannot sorb or diffuse. ${ }^{8}$ Furthermore in the amorphous regions, the diffusion mechanism is different according to whether the polymer is in a rubbery or a glassy state at the temperature of use. For example, highly augmented mass and gaseous transfers can occur during the hot-conditioning of food.

The crystallinity of PLA has been widely studied with respect to the morphology of the crystalline structure ${ }^{9-11}$ and to the influence of nucleating agents ${ }^{12}$ and plasticizers. ${ }^{13}$ The gaseous transfer of $\mathrm{O}_{2}, \mathrm{CO}_{2}$ and $\mathrm{H}_{2} \mathrm{O}$ through PLA films has already been investigated by several authors. ${ }^{14-20}$ The $\mathrm{CO}_{2}$ permeability coefficient of PLA is lower than that of polystyrene (PS), but higher than that of poly(ethylene terephthalate) (PET). ${ }^{14}$ A similar performance of PLA was described for $\mathrm{O}_{2} .{ }^{15,17}$ The barrier properties of PLA against water vapour, however, are not as good as those of PET and PS, although a decrease in the water permeability coefficient of PLA can be achieved by varying the film fabrication conditions.

\footnotetext{
Correspondence to: Sandra Domenek, UMR 1145 Ingiénerie Procédé Aliment (AgroParisTech/INRA/CEMAGREF/CNAM), 1 avenue des Olympiades, 91744 Massy, France.E-mail: sandra.domenek@agroparistech.fr

a Cnam, Laboratoire des Matériaux industriels polymers, 292 rue Saint-Martin, case courrier 322, 75141 Paris cedex 03, France

b UMR 1145 Ingiénerie Procédé Aliment(AgroParisTech/INRA/CEMAGREF/ (NAM), 1 avenue des Olympiades, 91744 Massy, France
} 
For example, an increase of temperature for biaxial oriented films results in a decrease of the water vapour permeability. ${ }^{15}$

The barrier properties of PLA against aroma compounds have been the subject of only a few studies to date. ${ }^{14,16}$ Auras and co-workers ${ }^{16}$ showed that PLA has an excellent performance against limonene, a hydrophobic aroma compound found in orange juice. However, more hydrophilic molecules, such as ethyl acetate, a booster and enhancer for fruit aroma often present in high quantity, can be sorbed to an approximately twofold greater extent in the hydrophilic polyester PLA in comparison to PET, polypropylene (PP) and low-density polyethylene (LDPE). Since aroma compounds are mainly hydrophobic molecules, PLA seems to be a promising material with efficient aroma barrier properties comparable to PET.

However, to date, the link between barrier properties and crystallinity has been the subject of only a few studies. No data have been published on the influence of the sorption of volatile organic molecules, such as aroma compounds, in PLA on its morphological and thermomechanical properties, particularly the influence on the glass transition. From an application point of view, this knowledge will be helpful in the design of PLA with efficient barrier properties not only in food packaging applications. Therefore, in the study reported here, PLA samples with various crystallinities were prepared and studied. An industrial sample of PLA film (Biophan ${ }^{\mathrm{TM}}$ ) was used as reference. For sample fabrication, the extrusion-thermocompression technique was preferred to the casting technique often used as a model process, in order to avoid a plasticizing effect due to the residual solvent which can affect the gas barrier properties. ${ }^{20}$ Ethyl acetate was used as a model volatile molecule, because it is used in high concentrations in many fruity aroma formulations where it plays an important role in the top note. It is the most hydrophilic molecule in the homologous series of ethyl esters used in aroma formulations. Oxygen barrier properties and ethyl acetate sorption were investigated as functions of the crystallinity of the PLA film. The thermomechanical consequences of ethyl acetate sorption were characterized using DSC and dynamic mechanical analysis (DMA).

\section{EXPERIMENTAL}

\section{Materials}

PLA Biophan $^{\text {TM }} 121$ film (Treofan, France) was provided as a film of $30 \mu \mathrm{m}$ in thickness being composed of three layers: a core layer of white PLA and two external layers of sealable PLA. It contained lactide monomers in D- and L-conformation, although the exact proportion was not specified in the manufacturer's datasheet. Its oxygen transmission rate was equal to $675 \mathrm{~cm}^{3} \mathrm{~m}^{-2}$ day ${ }^{-1} \mathrm{bar}^{-1}$ at $23^{\circ} \mathrm{C}$ and $50 \%$ relative humidity $(\mathrm{RH})$ according to the Treofan datasheet (oxygen permeability $P_{\mathrm{O} 2}=2.344 \times 10^{-18} \mathrm{~m}^{3} \mathrm{~m} \mathrm{~m}^{-2}$ $\mathrm{s}^{-1} \mathrm{~Pa}^{-1}$ ). PLA Biomer $\mathrm{L} 9000$ (Biomer, Germany), being mainly in the L-conformation and containing approximately $1 \%$ D-lactic acid, was purchased as pellets. An analysis of the molecular weight by size exclusion chromatography (SEC) resulted in the following characteristics: number-average molecular weight $\left(M_{n}\right)$ of 90000 and weight-average molecular weight $\left(M_{\mathrm{w}}\right)$ of 170000 . The pellets were dried at $80^{\circ} \mathrm{C}$ under vacuum for $8 \mathrm{~h}$ before use. Ethyl acetate and hexadecane (p.a. quality) were purchased from Sigma Aldrich (France).

\section{Extrusion and thermocompression of PLA films}

The extruded PLA film was prepared from dried Biomer pellets (vacuum pressure of $10^{4} \mathrm{~Pa}, 8 \mathrm{~h}$ at $80^{\circ} \mathrm{C}$ ) using a single-screw extruder of $30 \mathrm{~mm}$ in diameter with a barrel of length-to-diameter ratio of 33 and a three-section screw without mixing elements and turning at $40 \mathrm{rpm}$. The temperature profile of the six zones of the screw was $180-185-190-195-205-205^{\circ} \mathrm{C}$. The temperature profile of the mixer device (4 Sulzer SMX ${ }^{\circledR}$ ) and the die was defined at $210^{\circ} \mathrm{C}$, in order to avoid non-melted particles and degradation. A flat die of $100 \mathrm{~mm}$ in width and chill roll equipment were used to manufacture a film of $80 \mathrm{~mm}$ in width and approximately $190 \mu \mathrm{m}$ in thickness. The roll temperature and roll speed were fixed, respectively, at $25^{\circ} \mathrm{C}$ and $10 \mathrm{~m} \mathrm{~min}^{-1}$.

In order to obtain a PLA film sample with defined crystallinity and without residual stress, the extruded film was subsequently reheated and moulded using a thermal press (Specac Press, UK). Extruded films were sandwiched between a Teflon film and a stainless steel plate. The sandwich was held at $200^{\circ} \mathrm{C}$ for $1 \mathrm{~min}$ without pressure to ensure temperature equilibrium and complete melting of PLA. Then, a pressure of $3.4 \mathrm{bar}(340 \mathrm{kPa}$ ) was applied for $4 \mathrm{~min}$. The film was subsequently quenched in water at room temperature $\left(23^{\circ} \mathrm{C}\right)$ yielding amorphous, quenched PLA. In the following this sample will be referred to as quenched PLA. The quenched samples where reheated at various temperatures and durations under compression (0.5 bar $(50 \mathrm{kPa})$ ) to obtain PLA samples with various degrees of crystallinity. The recrystallized samples were quenched in water at room temperature. These samples will be referred to as recrystallized PLA. Sample thickness was measured with a handheld micrometer to be $190 \pm 30 \mu \mathrm{m}$.

\section{Conditioning of PLA films in ethyl acetate atmosphere}

The PLA samples were equilibrated in an ethyl acetate atmosphere at an activity of 0.5 for 3 days in a hermetic cell at $25^{\circ} \mathrm{C}$. The activity was calculated as $p / p_{0}$, with $p$ being the partial pressure and $p_{0}$ the vapour pressure of ethyl acetate at saturation. The duration of 3 days was a minimum time span to ensure the equilibration of the ethyl acetate concentration gradient within the samples. The activity of ethyl acetate in the atmosphere of the equilibration cell was generated with a solution in hexadecane containing $3.3 \times 10^{-2} \mathrm{~mol} \mathrm{~L}^{-1}$ ethyl acetate. An amount of $10 \mathrm{~mL}$ of this solution was put into a hermetic cell (volume of $0.8 \mathrm{~L}$ ) equipped with a Mininert ${ }^{\circledR}$ valve. The concentration of ethyl acetate in the atmosphere was measured after equilibration for $6 \mathrm{~h}$ at $25^{\circ} \mathrm{C}$. For that, $0.5 \mathrm{~mL}$ of the atmosphere was withdrawn using a gas syringe through the Mininert valve and analysed using a Fisons GC 8000 gas chromatograph (Fisons, France) equipped with a DB-Wax capillary column (J\&W Science; $30 \mathrm{~m}$ length $\times 0.32 \mathrm{~mm}$ inner diameter $\times 0.50 \mu \mathrm{m}$ film thickness). The temperature of the splitless/split injector was $220^{\circ} \mathrm{C}$ with a purge time of $1.5 \mathrm{~min}$. The temperature of the flame ionization detector was $250^{\circ} \mathrm{C}$. The carrier gas was hydrogen with a linear velocity of $37 \mathrm{~cm} \mathrm{~s}^{-1}$. The oven temperature was programmed to increase from 40 to $130^{\circ} \mathrm{C}$ at $5^{\circ} \mathrm{C} \mathrm{min}^{-1}$.

The concentration of ethyl acetate was calculated by external calibration. The calibration curve of ethyl acetate was set up by injection of $2 \mu \mathrm{L}$ of the calibration solutions which were ethyl acetate in pentane (Sigma, France, p.a. quality; 0.216, 0.433, 0.649 and $0.866 \mathrm{~mol} \mathrm{~L}^{-1}$ ). Ethyl acetate activity was determined using the perfect gas law.

\section{Analysis methods}

Size exclusion chromatography

The molecular weight of the polymer samples was determined using SEC with a Shimadzu liquid chromatograph equipped 
with an LC-10AD isocratic pump, a DGU-14A degasser, an SIL10AD automated injector and a CTO-10A thermostat oven. The fractionation was performed on a series of two PL-Gel mixed C $(5 \mu \mathrm{m}, 300 \mathrm{~mm})$ columns and a PL-100A $(300 \mathrm{~mm})$ column (Polymer Laboratories) preceded by a pre-column PL-Gel $5 \mu \mathrm{m}$ Guard (50 mm, Polymer Laboratories) using chloroform (Merck, HPLC grade) as elution solvent. The flow rate was $0.8 \mathrm{~mL} \mathrm{~min}^{-1}$, temperature was $25^{\circ} \mathrm{C}$ and injection volume was $100 \mu \mathrm{L}$. The fractions were detected using a Shimadzu RID-10A refractive index detector. Sample concentration was $4-5 \mathrm{mg} \mathrm{mL}^{-1}$. The system was calibrated with a polystyrene calibration kit of low polydispersity (580-1650000).

\section{Differential scanning calorimetry}

The crystallinity of the PLA samples was measured using a Pyris 1 (Perkin Elmer, France) DSC instrument. Tests were performed at $10{ }^{\circ} \mathrm{C} \mathrm{min}$ m $^{-1}$ from 0 to $200{ }^{\circ} \mathrm{C}$ in hermetic aluminium pans. The degree of crystallinity $\left(\chi_{c}\right)$ of the PLA samples was calculated using

$$
\chi_{\mathrm{c}}=\frac{\Delta H_{\mathrm{m}}-\Delta H_{\mathrm{c}}}{\Delta H_{\mathrm{m}}^{0}}
$$

where $\Delta H_{\mathrm{m}}$ is the enthalpy of melting considering the small exothermal event at the beginning of the melting peak, $\Delta H_{c}$ is the enthalpy of crystallization and $\Delta H_{\mathrm{m}}{ }^{0}$ is the enthalpy of fusion per mole of repeating unit of perfect crystal of infinite size (totally crystalline polymer), being $93 \mathrm{~J} \mathrm{~g}^{-1}$. $^{18}$ The glass transition temperature was measured using temperature-modulated DSC (TMDSC) with a QSC 100 instrument (TA Instruments, France). The heating scan was performed under sinusoidal temperature modulation with a heating rate of $1{ }^{\circ} \mathrm{C} \mathrm{min}-1$, a period of $80 \mathrm{~s}$ and a modulation of $\pm 1.5^{\circ} \mathrm{C}$ between -30 and $90^{\circ} \mathrm{C}$. Hermetic aluminium pans (Tzero, TA Instruments) were used, which are able to withstand an internal pressure of $3 \mathrm{bar}(300 \mathrm{kPa})$. The absence of weight loss was verified for each experiment by weighing. All measurements were made in triplicate. Each apparatus was equipped with an intracooler in order to reach low temperatures. All tests were performed under nitrogen atmosphere.

\section{Dynamic mechanical analysis}

Tension measurements were carried out with a Tritec 2000 DMA instrument (Triton Technology, France) at a frequency of $1 \mathrm{~Hz}$ and $0.1 \%$ strain. Polymer samples $(10.25 \mathrm{~mm}$ long, $5 \mathrm{~mm}$ wide and $\mathrm{ca}$ $0.2 \mathrm{~mm}$ thick) were heated from -50 to $200^{\circ} \mathrm{C}$ at $2{ }^{\circ} \mathrm{C} \mathrm{min}-1$. The temperature of the glass transition was taken at the peak of the damping factor $(\tan \delta)$. Measurements were done in triplicate.

\section{Oxygen permeability}

The oxygen transmission rate was measured at $23^{\circ} \mathrm{C}$ and $0 \%$ RH using a Systech 8001 (France) apparatus. Measurements were done in duplicate.

\section{Sorption isotherm}

The sorption isotherm of ethyl acetate was measured at $25^{\circ} \mathrm{C}$ and $0 \% \mathrm{RH}$ with a static method, using an electronic microbalance (Intelligent Gravimetric Analyzer 002, Hiden Isochema Ltd, Warrington, UK) with a sensitivity of $0.2 \mu \mathrm{g}$. Film samples (30-40 mg) were suspended from the microbalance by a stainless steel spiral which was contained in a thermoregulated cell at $25^{\circ} \mathrm{C}$. The microbalance itself was maintained at $50{ }^{\circ} \mathrm{C}$ to ensure stability during the weight measurement by prevention of solvent condensation. Before measurements, the samples were purged for $24 \mathrm{~h}$ at $10^{-5} \mathrm{mbar}\left(10^{-3} \mathrm{~Pa}\right)$ to remove all volatile compounds sorbed in the film and present in the chamber. Then, in order to set the aroma activity, the ethyl acetate partial pressure was set using a pressure transducer (Baratron ${ }^{\circledR}$, MKS Instruments, Wilmington, MA, USA) linked to a tank with a vapour phase saturated in ethyl acetate. The mass uptake of samples was recorded automatically with the time. The sorption equilibrium was defined as less than $1 \%$ change in the film mass or after $20 \mathrm{~h}$, even if the macroscopic equilibrium was not reached. The apparent ethyl acetate solubility $S\left(\mathrm{~kg} \mathrm{~m}^{-3} \mathrm{~Pa}^{-1}\right)$ was calculated according to

$$
S=M_{\infty} \times \frac{d}{p}
$$

where $M_{\infty}$ is the equilibrium sorption obtained theoretically after infinite time $\left(\mathrm{kg} \mathrm{kg}^{-1}\right), d$ is the film density $\left(\mathrm{kg} \mathrm{m}^{-3}\right)$ and $p$ is the compound vapour partial pressure $(\mathrm{Pa})$. Each measurement was done in triplicate.

The microbalance was calibrated regularly during maintenance periods for pressure, mass and temperature by the following methods.

- The microbalance weight measurement was calibrated using three Class F1 calibrated weights of 20,50 and $100 \mathrm{mg}$. Nine measurements were made with different combinations of the three weights to check the balance linearity as well as the microbalance measurement span by use of a least squares fit.

- The loading of a single F1 calibrated weight of $100 \mathrm{mg}$, with tolerance of $50 \mu \mathrm{g}$, was used to check the balance conformance. Typically the determined weight was within $\pm 20 \mu \mathrm{g}$ of the nominal value.

- The 100 mbar Baratron ${ }^{\circledR}$ capacitance manometer was factory calibrated, with a specified accuracy of $0.15 \%$ of reading.

- The sample temperature is measured using a platinum resistance thermometer (PT100 1/10 Class B) adjacent to the sample position. The measurement electronics span and offset were determined using high-precision resistances, individually calibrated using a traceable ohmmeter. The platinum resistance thermometer sensor conformance was verified to within $0.2^{\circ} \mathrm{C}$ by immersion in a distilled water/ice mix and by comparison with a calibrated glass thermometer at ambient temperature.

- The drift of the microbalance was estimated using a blank experiment to be $0.07 \mathrm{mbar}^{\mathrm{min}^{-1}}$.

\section{Statistical analysis}

Statistical analysis was done with a one-way analysis of variance (ANOVA). When the differences were significant $(p<0.05)$, Duncan's test was used to check the differences between pairs of groups and was carried out using XLSTAT-Pro 7.0 software (Addinsoft, Paris, France).

\section{RESULTS AND DISCUSSION}

\section{Sample preparation}

In order to test the influence of the crystallinity of PLA samples on barrier properties, PLA films with various crystallinities were fabricated by thermocompression of extruded films. Because PLA exhibits low crystallization kinetics, it is easy to prepare film samples with various degrees of crystallinity. The high glass transition temperature at approximately $60^{\circ} \mathrm{C}$ allows the 
Table 1. Influence of recrystallization conditions on the thermal properties of PLA films and oxygen permeability

\begin{tabular}{lcccccccc} 
Sample & \multicolumn{1}{c}{$T_{\mathrm{c}}$} & $\Delta H_{\mathrm{c}}\left(\mathrm{J} \mathrm{g}^{-1}\right)$ & $T_{\mathrm{m}}$ & $\Delta H_{\mathrm{m}}\left(\mathrm{J} \mathrm{g}^{-1}\right)$ & $\chi_{\mathrm{c}}(\%)$ & $M_{\mathrm{n}}$ & $M_{\mathrm{w}}$ & $\left.\mathrm{m}^{3} \mathrm{~m} \mathrm{~m}^{-2} \mathrm{~s}^{-1} \mathrm{~Pa}^{-1}\right)$ \\
\hline Extruded film & $100.5( \pm 0.2)$ & $33.4( \pm 0.4)$ & $164.3( \pm 2.8)$ & $35.5( \pm 0.2)$ & $2( \pm 1)$ & 97000 & 170000 & $1.94( \pm 0.03)^{\mathrm{a}}$ \\
Quenched PLA & $97.9( \pm 0.6)$ & $31.9( \pm 0.7)$ & $166.5( \pm 0.4)$ & $37.7( \pm 0.8)$ & $6 \%( \pm 2)$ & 92000 & 175000 & $2.50( \pm 0.18)^{\mathrm{b}}$ \\
$80^{\circ} \mathrm{C}, 15$ min recrystallized PLA & $91.6( \pm 0.8)$ & $30.0( \pm 1.3)$ & $166.9( \pm 1.7)$ & $37.2( \pm 0.5)$ & $8 \%( \pm 3)$ & n.d. & n.d. & n.d. \\
$85^{\circ} \mathrm{C}, 15$ min recrystallized PLA & $82.3( \pm 0.6)$ & $8.6( \pm 2.5)$ & $168.3( \pm 0.5)$ & $36.0( \pm 0.1)$ & $29 \%( \pm 4)$ & n.d. & n.d. & n.d. \\
$90^{\circ} \mathrm{C}, 15$ min recrystallized PLA & - & 0 & $165.7( \pm 1.4)$ & $36.0( \pm 0.2)$ & $39 \%( \pm 1)$ & n.d. & n.d. & n.d. \\
$92^{\circ} \mathrm{C}, 25$ min recrystallized PLA & - & 0 & $167.9( \pm 0.3)$ & $36.7( \pm 0.6)$ & $39 \%( \pm 1)$ & 80000 & 167000 & $2.86( \pm 0.08)^{\mathrm{c}}$ \\
PLA Biophan $^{\text {TM }}$ & - & 0 & $138.9( \pm 0.7)$ & $17.9( \pm 0.1)$ & $19 \%( \pm 1)$ & 90000 & 172000 & $2.11( \pm 0.08)^{\mathrm{a}}$ \\
\hline
\end{tabular}

$T_{\mathrm{c}}$, crystallization temperature; $\Delta H_{\mathrm{c}}$, crystallization enthalpy; $T_{\mathrm{m}}$, melting temperature; $\Delta H_{\mathrm{m}}$, melting enthalpy; $\chi_{\mathrm{c}}$, degree of crystallinity; $P_{\mathrm{O} 2}$, oxygen permeability; n.d., not determined.

a,b,c Significant differences at $p<0.05$ (Duncan's test).

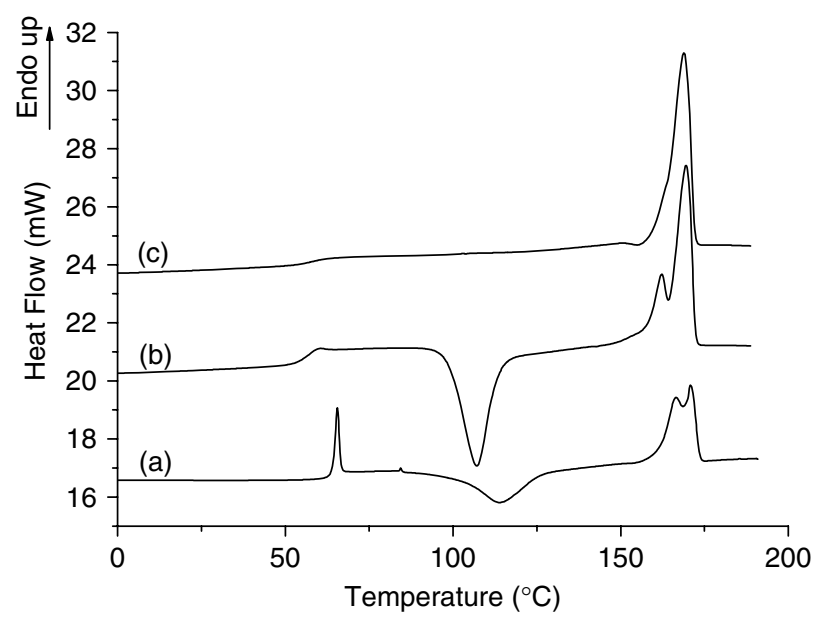

Figure 1. Heat flow curves of PLA samples in the first heating cycle: (a) extruded PLA; (b) quenched PLA; (c) recrystallized PLA $\left(92^{\circ} \mathrm{C}, 25 \mathrm{~min}\right)$.

quenching of the PLA samples from the melt at room temperature. Samples were subsequently annealed at various temperatures and times. The operation conditions used in this work are given in Table 1. The annealing temperatures were low in order to obtain small spherulites giving generally better mechanical properties. The annealing time was limited in order to limit sample degradation. Table 1 shows the molecular weight characteristics of the different samples. The extrusion and thermocompression treatment results in a decrease of molecular weight.

Figure 1 shows heating scans of three samples: extruded PLA (curve a), quenched PLA (curve b) and PLA crystallized in the heating press (curve $c$ ). The heating scan of the extruded PLA shows an endothermic relaxation event that is superposed on the glass transition temperature $\left(T_{\mathrm{g}}\right)$, preventing the determination of the $T_{\mathrm{g}}$ value. Annealing the samples at temperatures higher than $T_{\mathrm{g}}$ nearly eliminated the endothermic relaxation (curves $\mathrm{b}$ and $\mathrm{c}$ ), which is a result of a secondary molecular reordering occurring in the amorphous phase of semi-crystalline polymers. ${ }^{15}$ The extruded and quenched PLA (curves $a$ and $b$ ) show a cold crystallization at ca $100^{\circ} \mathrm{C}$ and a double melting endotherm at ca $170^{\circ} \mathrm{C}$. The double melting peak of PLA has been studied using modulated DSC. ${ }^{10,22}$ The current interpretation is a melting-recrystallization phenomenon where the lower endotherm corresponds to the melting of initially present crystals. The partially molten material is thought to be able to recrystallize forming more perfect crystals melting at higher temperature in the second endotherm. 1,10,11,23 Melting of all PLA samples is accompanied by a small exothermal event. This exothermal signal overlapping is well observed in TMDSC and has been previously reported by Zuza et al. ${ }^{24}$ and Ohtani et al. ${ }^{25}$ It has been suggested that the cause is the recrystallization of already existing $\alpha$ crystals into an $\alpha$ polymorph of higher perfection. ${ }^{25}$

The thermal properties of our PLA samples are given in Table 1. The degree of crystallinity is calculated according to Eqn (1). We notice that the crystallization temperature $\left(T_{c}\right)$ and melting temperature $\left(T_{\mathrm{m}}\right)$ do not change with annealing temperature. Values of $\Delta H_{\mathrm{m}}$ are similar for all PLA Biomer samples which illustrates the absence of degradation of polymer during sample preparation because there is no change in the ability of PLA to crystallize. Similar conclusions have been drawn for the polyester PET. ${ }^{26}$ Values of $\Delta H_{\mathrm{c}}$ decrease with the heating temperature which permits one to follow the crystallization process and to calculate the increase of the degree of crystallinity. On the one hand, as expected, $\Delta H_{\mathrm{c}}$ decreases with the annealing temperature which permits one to follow the crystallization process with an increase of the degree of crystallinity. On the other hand, $\Delta H_{\mathrm{m}}$ values are similar which illustrates the absence of degradation for all samples based on PLA Biomer during sample preparation. These results show that there is no change in the ability of PLA to crystallize which is in accordance with previous work on PET. ${ }^{26}$ The maximum degree of crystallinity realizable with our experimental set-up is approximately $40 \%$ which is in accordance with the results of Ling and Spruiell ${ }^{11}$ and MacDonald et al. ${ }^{27}$ No difference between the sample annealed at $90^{\circ} \mathrm{C}$ for $15 \mathrm{~min}$ and that annealed at $92^{\circ} \mathrm{C}$ for $25 \mathrm{~min}$ is observed in the DSC analysis.

The impact of crystallization on the viscoelastic properties of the PLA samples was further investigated using thermomechanical analysis. Figure 2 plots curves of uniaxial tensile storage modulus $\left(E^{\prime}\right)$ as a function of temperature. The sample recrystallized at $92^{\circ} \mathrm{C}$ shows the highest $E^{\prime}$ in the glassy plateau. The loss of $E^{\prime}$ during the glass transition at approximately $60^{\circ} \mathrm{C}$ depends on the quantity of amorphous phase in the sample. We see that it is largest for the quenched PLA film. Incompletely recrystallized samples show an increase in $E^{\prime}$ after $T_{\mathrm{g}}$, which has been shown to be caused by the cold crystallization phenomenon. ${ }^{28}$ The recrystallization induces a stiffening of the macromolecular chains being responsible for the increase in the storage modulus. The final decrease of the storage modulus at high temperature corresponds to crystal melting in the film. DMA being a more sensitive technique than DSC to observe physical transition phenomena in polymers allows us to distinguish 


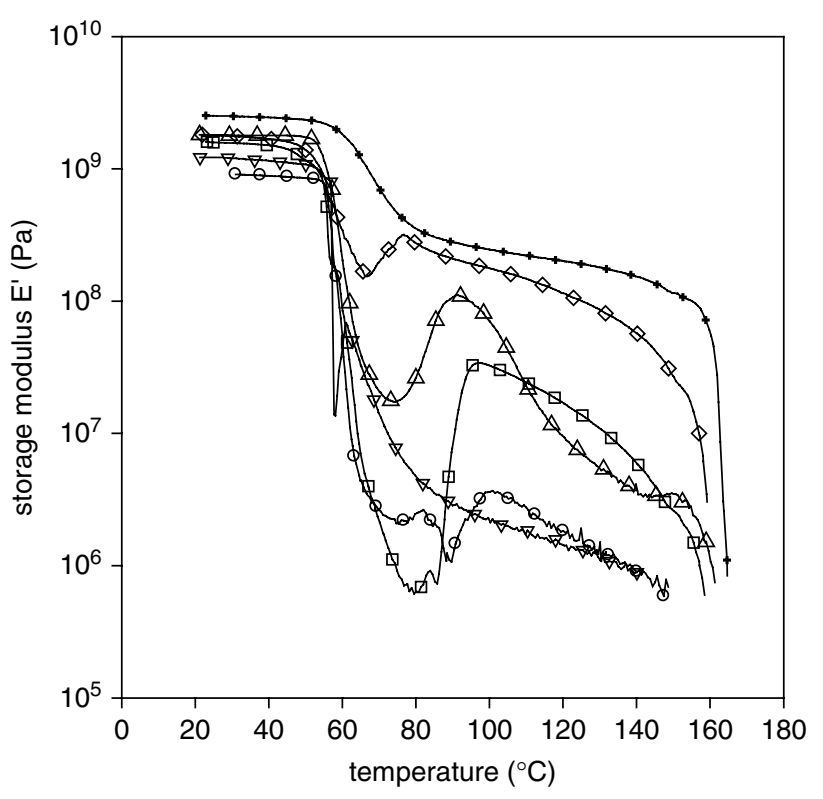

Figure 2. Evolution of the storage modulus with temperature of PLA samples having various crystallinities. Extruded PLA (O), quenched PLA ( $\square$ ) and annealed PLA: $15 \mathrm{~min}$ at $80^{\circ} \mathrm{C}(\triangle), 15 \mathrm{~min}$ at $85^{\circ} \mathrm{C}(\nabla), 15 \mathrm{~min}$ at $90^{\circ} \mathrm{C}$ $(\diamond)$ and 25 min at $92^{\circ} \mathrm{C}(+)$.

between the samples recrystallized at higher temperature. The sample compressed for $15 \mathrm{~min}$ at $90^{\circ} \mathrm{C}$ is still able to recrystallize as we can see from the peak of the storage modulus in the rubbery plateau, a phenomenon not observed in the curve of the sample treated at $92^{\circ} \mathrm{C}$.

To investigate of the effect of crystallinity on the barrier properties of the PLA films we worked on the extruded blank, the quenched sample and the film thermocompressed for $25 \mathrm{~min}$ at $92{ }^{\circ} \mathrm{C}$. The latter will be referred to as recrystallized film.

\section{Gas barrier properties}

The oxygen permeability of the various samples is given in Table 1. Literature data give oxygen permeabilities between $2.3 \times 10^{-18}$ and $4.6 \times 10^{-18} \mathrm{~m}^{3} \mathrm{~m} \mathrm{~m}^{-2} \mathrm{~s}^{-1} \mathrm{~Pa}^{-1}$ for various experimental setups. ${ }^{15,29,30}$ Our results are consistent with those data. The oxygen permeability of the PLA Biophan ${ }^{\mathrm{TM}}$ film is in accordance with the values given by the manufacturer. Compared to conventional packaging polymers, PLA shows behaviour intermediate between that of PET and PS, being, respectively, good oxygen barrier packaging with an oxygen permeability of ca $0.4 \times 10^{-18} \mathrm{~m}^{3}$ $\mathrm{m} \mathrm{m}^{-2} \mathrm{~s}^{-1} \mathrm{~Pa}^{-1}$ and a low oxygen barrier material with oxygen permeability of $19 \times 10^{-18} \mathrm{~m}^{3} \mathrm{~m} \mathrm{~m}^{-2} \mathrm{~s}^{-1} \mathrm{~Pa}^{-1}{ }^{31}$ The statistical analysis of the data, given in Table 1, shows that the films behave significantly different. The recrystallized sample has the highest oxygen permeability, which is not the expected result. For example, crystallization, in particular cold crystallization from the glassy state, is a common way to improve gas barrier properties of PET. ${ }^{32}$ Furthermore, a decrease of the water vapour transfer rate with increasing crystallinity has already been shown for PLA. ${ }^{33}$ The decrease of the gas permeability with crystallinity is generally explained in terms of two factors. First, the inclusion of impermeable crystallites decreases the amount of the amorphous phase through which gas molecules can permeate. Second, impermeable crystals increase the tortuosity of the transport path. The former effect affects the total solubility of the permeant in the material, the later affects the diffusion coefficient. However, in many cases the decrease of solubility with crystallinity is smaller than expected from the increase of crystallinity. This behaviour is explained by the decrease of the average amorphous phase density or de-densification with increasing crystallinity resulting from conformational restrictions imposed by the crystallinity on the polymer chain in the amorphous phase. The less dense amorphous phase includes higher free volume and shows therefore higher gas solubility. ${ }^{34}$

In our case, an increase of oxygen permeability is observed. Although significant after three measurements, the increase is very small, because, from a technological point of view, a relevant effect includes the change of an order of magnitude in permeability. We propose two hypotheses for our findings. First, although the DSC and DMA results clearly show the crystallinity of the recrystallized PLA, no apparent spherulites are observed with a microscope under cross-polarized light, which is in contrast to the observations of Solarski et al. ${ }^{21}$ or Tsuji and Ikada. ${ }^{35}$ The morphology can be explained by the low recrystallization temperature used in this work to obtain small spherulites. Therefore, we suggest that the spherulites in our film samples might be too small to create a more tortuous path for the oxygen molecules and thus to decrease the gas permeability. It has been described for PET that an increase in the size of the superstructure in the crystalline phase decreases the gas permeability due to an increase of the tortuosity. ${ }^{32}$

A second hypothesis might be the de-densification of the amorphous phase which counteracts the decrease of the quantity of permeable amorphous phase due to crystallization. Dedensification of the amorphous phase in PET has been shown by Liu et al. ${ }^{36}$ to be responsible for the higher oxygen permeability of bottle walls processed under conditions of higher thermal exposure, although the treatment led to an increase in the volume fraction of impermeable crystals. A decrease in the permeable amorphous phase density causing an increase of gas permeability through heat-set PET was also shown by Qureshi et al. ${ }^{37}$ It has been shown for poly(L-lactic acid) (PLLA), in comparison to PET, that there is an important decoupling between crystalline and surrounding amorphous phase. ${ }^{24,38,39}$ This behaviour is attributed to the high flexibility of the macromolecular chain, which is able to fold easily on the crystal surface. The result would be less tied molecules between amorphous and crystalline phase, ${ }^{38}$ a factor limiting the possibility of de-densification of the amorphous phase. Further research and careful measuring of the phase densities of PLA should be carried out in order to get more insight into the transport mechanisms.

\section{Aroma compound sorption}

The mass uptake of ethyl acetate in the PLA samples is plotted in Fig. 3. The plots show an upwards trend and are convex in relation to the ethyl acetate activity axis. In the case of semi-crystalline polymers in their glassy state, the sorption isotherm at low partial pressures of penetrant is concave to the pressure axis and convex only at high activities. ${ }^{40}$ This behaviour is generally described by the dual-mode sorption model (combination of Henry's and Langmuir's sorption modes). At high penetrant activities, the convex form is usually described for semi-crystalline polymers in their rubbery state, such as hydrophobic polymers in contact with organic compounds. Examples for this type of sorption isotherm are the sorption of ethyl acetate and ethyl hexanoate into LDPE ${ }^{41}$ or benzaldehyde into PP. ${ }^{42}$ The behaviour is generally described with the Flory-Huggins or the engaged species induced clustering (ENSIC) model. ${ }^{43}$ Fig. 3 shows that the comparative data obtained 


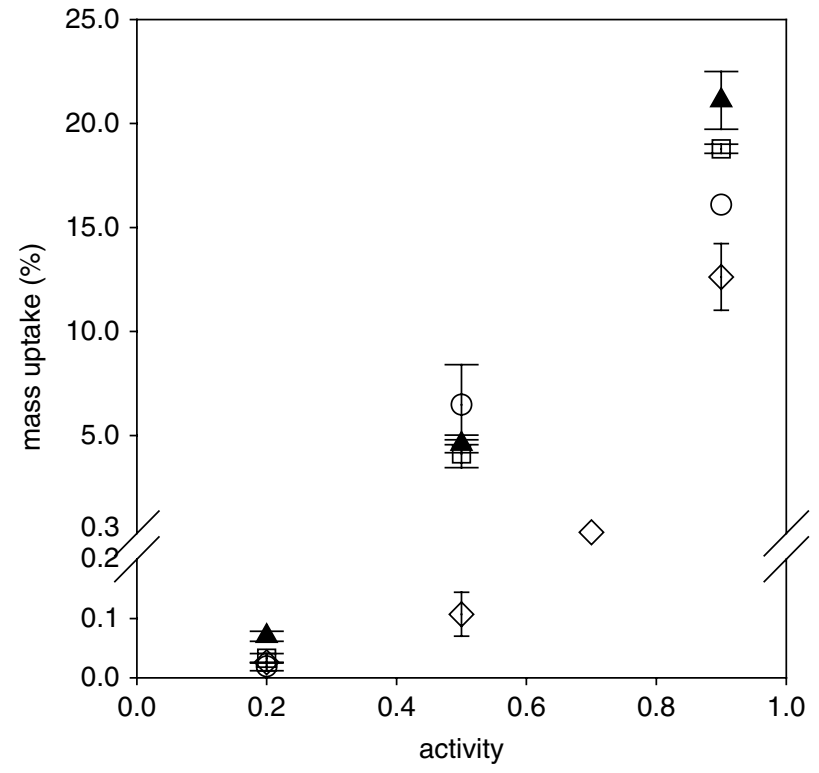

Figure 3. Apparent sorption isotherm of ethyl acetate in PLA samples with various crystallinities. In order to display the differences for small values, the ordinate is discontinuous between 0.2 and $0.3 \%$ mass uptake (kg ethyl acetate per kg polymer). Extruded PLA (O), quenched PLA ( $\square$ ), recrystallized PLA $(\diamond)$, PLA Biophan ${ }^{\mathrm{TM}}(\mathbf{\Lambda})$.

after $20 \mathrm{~h}$ of sorption seem to be consistent with an ENSIC or Flory-Huggins sorption isotherm.

At an activity of 0.5 , the recrystallized PLA film shows an ethyl acetate mass uptake significantly lower than that of the other PLA films. The mass uptake of the recrystallized sample remains small compared to the other samples up to an activity of 0.7 . Between activities of 0.7 and 0.9 the sorption of ethyl acetate increases strongly. We suggest that this is caused by a change in the sorption mechanism due to the formation of ethyl acetate clusters in the polymer, which is consistent with the ENSIC model. At an activity of 0.9 , there is a difference between the sorption of all samples, with the recrystallized film sorbing the smallest and the PLA Biophan ${ }^{\mathrm{TM}}$ film the highest quantity. The reason why the Biophan $^{\mathrm{TM}}$ film sorbs more than the amorphous samples could not be determined. Various hypotheses can be suggested. The exact formulation of the Biophan ${ }^{\mathrm{TM}}$ film is not known; technical adjuvant contained in the polymer may enhance ethyl acetate sorption. Furthermore, the film has two sealable faces which are amorphous, probably accounting for a major part of the sorption. A second hypothesis is the comparatively small thickness of the sample. The thermocompressed PLA Biomer samples are fivefold thicker, which may induce an error in the apparent solubility coefficient because the macroscopic equilibrium value is not reached.

The kinetics of the sorption allow us to calculate the apparent solubility coefficients $(S)$ of ethyl acetate in the PLA samples at various activities $\left(p / p_{0}\right)$ according to Eqn (2). However, the PLA samples reach the stationary state of the sorption curve only at an activity of 0.2 . In order to compare the behaviour of the PLA samples, the apparent solubility coefficients were calculated from the near-equilibrium value of the mass uptake after $20 \mathrm{~h}$ of contact. The results are shown in Fig. 4.

The recrystallized sample sorbs the smallest quantity of ethyl acetate whatever the activity, because the sorption occurs only in the amorphous phase of the polymer. The results at an activity of 0.5 are of the same order of magnitude as the results of Auras

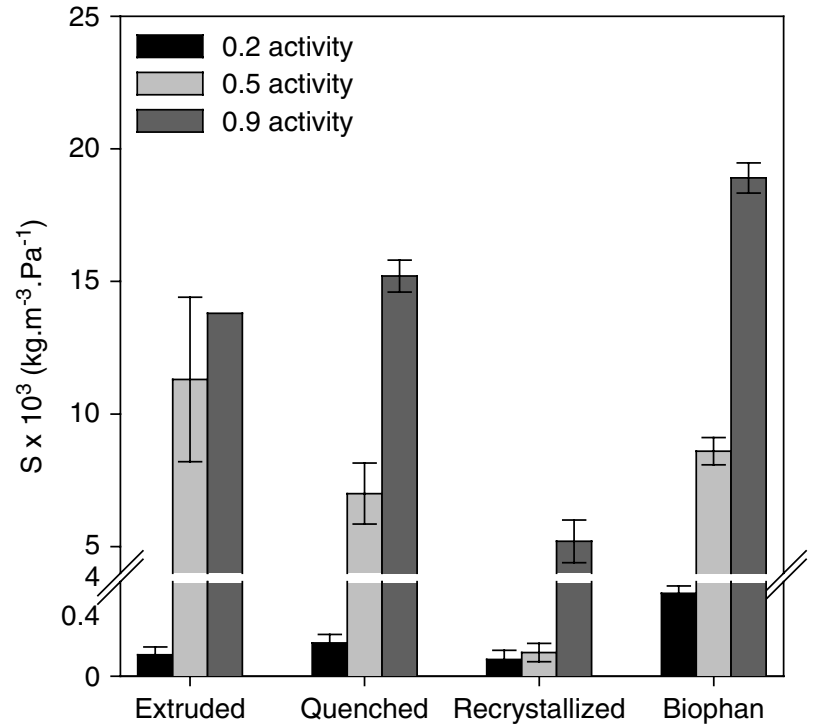

Figure 4. Apparent solubility coefficient $(S)$ of ethyl acetate in PLA samples with varying crystallinity at three activities $\left(p / p_{0}\right)$ at $25^{\circ} \mathrm{C}$. In order to display the small values, the ordinate is discontinuous as indicated.

et al. ${ }^{16}$ who measured, using a different experimental set-up, a solubility coefficient of $6.17 \times 10^{-3} \mathrm{~kg} \mathrm{~m}^{-3} \mathrm{~Pa}^{-1}$ at $30^{\circ} \mathrm{C}$ and an activity of 0.3 for PLA $98 \%$ L-isomers. In comparison, the solubility coefficients of ethyl acetate in the PLA samples are higher than those obtained in LDPE and PP. The solubility coefficient of the rather hydrophilic molecule ethyl acetate in those hydrophobic polymers ranges from $1.52 \times 10^{-3} \mathrm{~kg} \mathrm{~m}^{-3} \mathrm{~Pa}^{-1}$ at an activity of 0.5 to $1.92 \times 10^{-3} \mathrm{~kg} \mathrm{~m}^{-3} \mathrm{~Pa}^{-1}$ at an activity of 0.9 . $^{41}$ Nielsen and Giacin ${ }^{44}$ measured the solubility coefficient of ethyl acetate in PP using a gravimetric procedure at an activity of 0.5 and $22^{\circ} \mathrm{C}$ as equal to $3.2 \times 10^{-3} \mathrm{~kg} \mathrm{~m}^{-3} \mathrm{~Pa}^{-1}$. These comparisons show that the ethyl acetate solubility is roughly two times higher in PLA compared to the polyolefins PP and PE. The reason is most probably the more hydrophilic character of the PLA chains which facilitates the sorption of the comparatively hydrophilic molecule ethyl acetate. Actually, ethyl acetate is the most hydrophilic aroma compound in the homologous series of ethyl esters, and it was chosen here in order to test the performance of PLA in a rather unfavourable case. Since aroma compounds are in the main more hydrophobic than ethyl acetate, good performance of the barrier properties of PLA can be expected. Auras et al. ${ }^{16}$ showed, for example, that the sorption of hydrophobic limonene in PLA was apparently smaller than that in LDPE and PP.

\section{Influence of aroma compound sorption on the thermal properties of PLA}

The form of the sorption isotherm consistent with the ENSIC model suggests the plasticizing of the polymer matrix. In order to test the effect of sorption on the thermomechanical properties of the PLA samples, they were analysed after 3 days equilibration in ethyl acetate atmosphere at an activity of 0.5 . The results are given in Table 2. The glass transition temperature was measured using TMDSC which allows the determination in the first heating scan although the enthalpic relaxation peak is superposed on the $T_{\mathrm{g}}$ signal as shown in Fig. 1. Figure 5 shows the heat flow curve of the various samples before (Fig. 5(a)) and after (Fig. 5(b)) equilibration in ethyl acetate atmosphere. One observes the broadening of the 
Table 2. Glass transition temperature $\left(T_{\mathrm{g}}\right)$ and degree of crystallinity of PLA films determined using DSC and DMA before and after sorption of ethyl acetate (EA) during the conditioning in EA atmosphere at an activity of 0.5 and $25^{\circ} \mathrm{C}$ for 3 days

\begin{tabular}{|c|c|c|c|c|c|c|}
\hline \multirow[b]{2}{*}{ Sample } & \multicolumn{2}{|c|}{ Crystallinity (\%) } & \multicolumn{2}{|c|}{ DSC } & \multicolumn{2}{|c|}{ DMA } \\
\hline & $\begin{array}{l}\text { Before EA } \\
\text { sorption }\end{array}$ & $\begin{array}{l}\text { After EA } \\
\text { sorption }\end{array}$ & $\begin{array}{c}T_{\mathrm{g}}\left({ }^{\circ} \mathrm{C}\right) \text { before } \\
\text { EA sorption }\end{array}$ & $\begin{array}{l}T_{\mathrm{g}}\left({ }^{\circ} \mathrm{C}\right) \text { after } \\
\text { EA sorption }\end{array}$ & $\begin{array}{c}T_{\mathrm{g}}\left({ }^{\circ} \mathrm{C}\right) \text { before } \\
\text { EA sorption }\end{array}$ & $\begin{array}{l}T_{\mathrm{g}}\left({ }^{\circ} \mathrm{C}\right) \text { after } \\
\text { EA sorption }\end{array}$ \\
\hline Extruded PLA & $2( \pm 1)$ & $46( \pm 5)^{\mathrm{a}}$ & $56.7( \pm 0.6)$ & $-0.3( \pm 8.8)^{\mathrm{a}}$ & $62.3( \pm 0.2)$ & $52.1( \pm 1.1)^{\mathrm{b}}$ \\
\hline Quenched PLA & $6( \pm 2)$ & $46( \pm 2)^{\mathrm{a}}$ & $56.8( \pm 1.3)$ & $1.9( \pm 5.9)^{\mathrm{a}, \mathrm{b}}$ & $62.8( \pm 0.3)$ & $49.8( \pm 0.4)^{c}$ \\
\hline Recrystallized PLA & $39( \pm 1)$ & $52( \pm 3)^{a}$ & $63.3( \pm 1.2)$ & $-5.7( \pm 0.3)^{\mathrm{a}}$ & $71.2( \pm 2.2)$ & $52.0( \pm 0.1)^{b, c}$ \\
\hline PLA Biophan ${ }^{\mathrm{TM}}$ & $19( \pm 1)$ & $22( \pm 4)^{b}$ & $50.9( \pm 0.1)$ & $16.9( \pm 1.9)^{\mathrm{b}}$ & $67.9( \pm 0.1)$ & $55.2( \pm 0.1)^{\mathrm{a}}$ \\
\hline
\end{tabular}

a,b,c Significant differences at $p<0.05$ (Duncan's test).

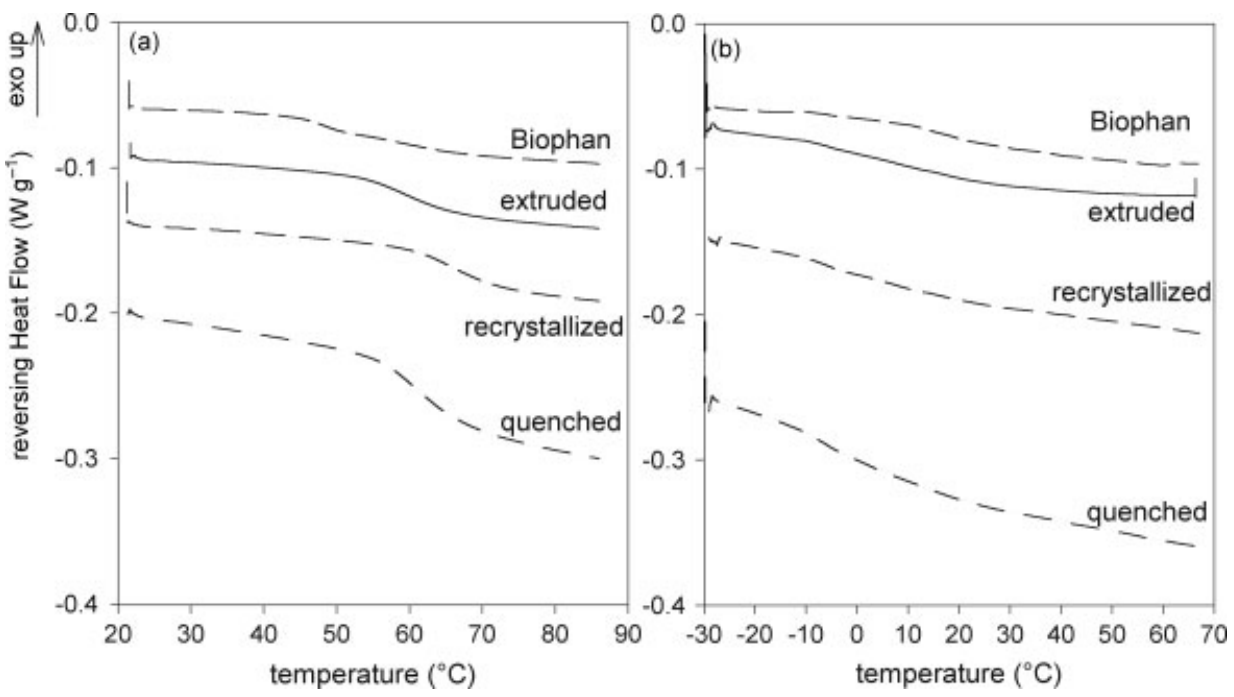

Figure 5. Heat flow curves of PLA samples (a) before and (b) after equilibration in ethyl acetate atmosphere at an activity of 0.5 and $25^{\circ} \mathrm{C}$ for 3 days.

glass transition region to more than $20^{\circ} \mathrm{C}$. This flat transition is easier to determine in the modulated heating scan.

We note an increase of $T_{\mathrm{g}}$ with increasing crystallinity for the PLA Biomer samples before conditioning in ethyl acetate atmosphere. This increase is consistent with the results of Delpouve et al. ${ }^{45}$ Those authors showed that there was a complex polymer relaxation phenomenon indicating two distinct glass transition dynamics. The low-temperature process is assigned to segmental motions in the interspherulitic amorphous phase and the hightemperature process can be assigned to the presence of an intraspherulitic amorphous phase being more constrained. Zuza et al. ${ }^{24}$ found a similar increase of $T_{\mathrm{g}}$ for semi-crystalline PLA. They showed furthermore a shift of $15^{\circ} \mathrm{C}$ to higher temperatures of $T_{\mathrm{g}}$ of semi-crystalline PLLA compared to amorphous poly(D,L-lactic acid), which may explain the observed difference between the recrystallized sample and PLA Biophan ${ }^{\mathrm{TM}}$. If we turn our attention now to the $T_{\mathrm{g}}$ results after conditioning of the PLA samples in ethyl acetate atmosphere, no significant difference in $T_{\mathrm{g}}$ as a function of crystallinity is observed, except PLA Biophan ${ }^{\mathrm{TM}}$, as is evident from the statistical analysis in Table 2. However, the broadening of the glass transition leads to a higher uncertainty of the value of $T_{\mathrm{g}}$ taken at the midpoint of the transition. What is important here, especially for packaging applications of PLA, is the large shift of the value of $T_{\mathrm{g}}$ far below room temperature. Even if the shift of $T_{\mathrm{g}}$ of PLA Biophan ${ }^{\mathrm{TM}}$ is smaller, the value is still below room temperature. A very negative effect of the sorption of aroma compounds such as ethyl acetate on the barrier properties of packaging materials during the storage of food products can be expected. Actually, the transfer phenomena are known to accelerate at temperatures higher than $T_{\mathrm{g}}$. Table 2 also gives the $T_{\mathrm{g}}$ values recorded using DMA and obtained at the peak of the damping factor. The decrease of $T_{\mathrm{g}}$ after conditioning of the samples in ethyl acetate atmosphere is still important, but recorded values are much higher than those from DSC. A significant difference between PLA Biophan ${ }^{\mathrm{TM}}$ and the other samples is observed. Furthermore, there seems to be a difference between the quenched sample and the extruded and recrystallized ones. However, this difference is not confirmed by the DSC values, where problems of ethyl acetate evaporation are avoided. On the one hand, the results of the mechanical testing are generally higher than those from DSC; on the other hand, we suppose that samples dry during the DMA measurements. One reason is the large surface of the samples exposed to the surrounding air; a second is the smaller heating rate used and thus the longer time of exposure. Moreover, hermetic capsules were used for DSC analysis to avoid aroma evaporation, which is confirmed by the unchanged sample weight after the measurements.

Figure 6 plots the evolution of $E^{\prime}$ with temperature. We observe a broadening of the glass transition, a result also seen in the DSC analysis. The conditioning in ethyl acetate atmosphere has no impact on the value of $E^{\prime}$ in the glassy plateau, except for the recrystallized sample. $E^{\prime}$ after conditioning is even higher than 


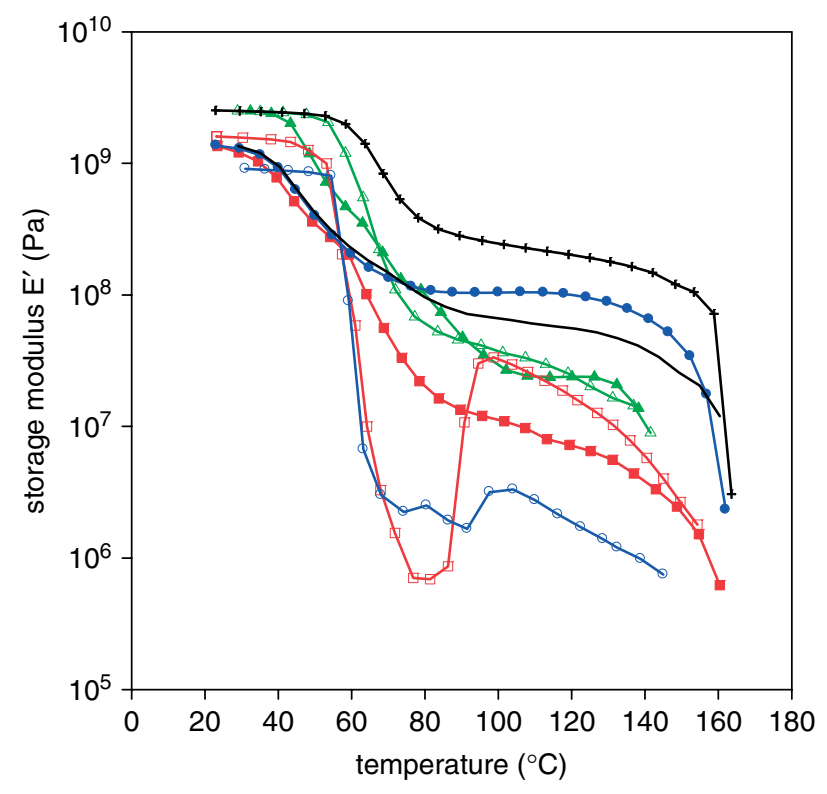

Figure 6. Thermomechanical properties of PLA films before (open symbols) and after (closed symbols) conditioning in ethyl acetate atmosphere at an activity of 0.5 and $25^{\circ} \mathrm{C}$ for 3 days. Extruded PLA (O), quenched PLA ( $\square$ ), recrystallized PLA (+, no symbol for conditioned sample), PLA Biophan $^{\mathrm{TM}}(\triangle)$.

the initial one for the extruded sample. What is interesting is the evolution of $E^{\prime}$ in the rubbery plateau. As already explained in the discussion of Fig. 2, we observe a peak in the modulus curve due to the cold crystallization of the sample before conditioning. Comparing to the equilibrated films, we find an increase in $E^{\prime}$ in the case of the quenched and the extruded samples and no cold crystallization peak. On the contrary, the moduli of the PLA Biophan ${ }^{\mathrm{TM}}$ and the recrystallized samples are lower after conditioning, which is expected due to the plasticizing of the polymer.

Our interpretation is that ethyl acetate induces crystallization of the PLA samples, which can explain the increase of the storage modulus in the rubbery plateau and the absence of the cold crystallization peak. Another result pointing to solvent-induced crystallization during the conditioning in ethyl acetate atmosphere is the whitening of the film samples.

The degree of crystallinity of the PLA samples before and after conditioning in ethyl acetate atmosphere calculated using Eqn (1) is given in Table 2. A clear increase of the degree of crystallinity up to the value of the recrystallized film is observed, and all PLA samples, except PLA Biophan ${ }^{\mathrm{TM}}$, are classified in the same statistical group. PLA Biophan ${ }^{\mathrm{TM}}$ shows no induced crystallization. We suggest that this behaviour might be caused by the different chirality of the Biophan ${ }^{\mathrm{TM}}$ sample, because the crystallization kinetics are strongly dependent on the D- and L-content of the copolymer. ${ }^{29}$

Solvent-induced crystallization has already been described for the semi-crystalline polyester PET, ${ }^{40,46-48}$ in particular by Serad et al. ${ }^{40}$ and by Ouyang et al. ${ }^{48}$ who showed the crystallization of PET in contact with acetaldehyde and acetone, respectively. Ouyang and Shore ${ }^{49,50}$ showed for the solvent-induced phenomenon that the sample dimensions increased after the sorption of the solvent due to swelling of the polymer. This caused the release of internal stress bringing about more mobility of the polymer chain and enabling crystallization at low temperature. In our case, in the same manner, the transport of ethyl acetate in amorphous PLA seems to be accompanied by the induced crystallization of the polymer.

\section{CONCLUSIONS}

PLA film samples (L-conformation) with various crystallinities were prepared by flat die extrusion and thermocompression and compared to PLA Biophan ${ }^{\mathrm{TM}}$ having D,L-conformation. Crystallinity does not seem to be the key factor for the improvement of the barrier properties of PLA against oxygen. The oxygen transfer rate of PLA Biophan ${ }^{\mathrm{TM}}$ was significantly different from that of the PLLA samples. However, the sorption of the aroma compound ethyl acetate decreased with increasing crystallinity. In this case, PLA Biophan ${ }^{\text {TM }}$ behaved like the amorphous PLLA samples. There are differences in the sorption mechanism of gaseous molecules, such as oxygen, and volatile organic compounds, because in the latter case the solubility coefficient has a dominating effect on the permeability. The sorption isotherm was compatible with the ENSIC model, which predicts the plasticizing of the polymer matrix. This was confirmed by DSC and DMA measurements, which showed moreover a solvent-induced crystallization of PLLA, evidencing a strong plasticizing effect. For the application of polyesters and more specifically PLA in food packaging, good barrier properties are required. Consequently the extent of the change of the thermomechanical properties of polymer matrix when brought into contact with organic compounds, such as aroma compounds, is an important finding. The important decrease of the glass transition of PLA upon the sorption of an aroma compounds well below ambient temperature has an impact on its barrier properties and thus the stability of food products at room temperature. This clearly shows the need to carefully optimize packaging material by taking into account the interaction of polymer matrix and packed foodstuff over the whole of the shelf-life.

\section{REFERENCES}

1 Peniston SJ and Choi SJ, J Biomed Mater Res B 80B:67-77 (2006).

2 Conn RE, Kolstad JJ, Borzelleca JF, Dixler DS, Filer Jr LJ, LaDu Jr BN, et al, Food Chem Toxicol 33:273-283 (1995).

3 Sajilata MG, Savitha K, Singhal RS and Kanetkar VR, Compr Rev Food Sci Food Saf 6:17-35 (2007).

4 Dury-Brun C, Chalier P, Desobry S and Voilley A, Food Rev Int 23:199-255 (2007).

5 Berlinet C, Ducruet V, Brillouet JM, Reynes M and Brat P, Food Addit Contam 22:185-195 (2005).

6 Ducruet V, Vitrac O, Saillard P, Guichard E, Feigenbaum A and Fournier N, Food Addit Contam 24:1306-1317 (2007).

7 Saint-Eve A, Levy C, Le Moigne M, Ducruet V and Souchon I, Food Chem 110:285-293 (2008).

8 Michaels AS and Bixler HJ, J Polym Sci 50:393-412 (1961).

9 De Oca HM and Ward IM, J Polym Sci B: Polym Phys 45:892-902 (2007).

10 Ling X and Spruiell JE, J Polym Sci B: Polym Phys 44:3378-3391 (2006).

11 Ling X and Spruiell JE, J Polym Sci B: Polym Phys 44:3200-3214 (2006).

12 Pluta M, Jeszka JK and Boiteux G, Eur Polym J 43:2819-2835 (2007).

13 Martino VP, Ruseckaite RA and Jimenez A, J Therm Anal Calorim 86:707-712 (2006).

14 Auras RA, Harte B, Selke S and Hernandez R, J Plast Film Sheeting 19:123-135 (2003).

15 Auras RA, Singh SP and Singh JJ, Packag Technol Sci 18:207-216 (2005).

16 Auras R, Harte B and Selke S, J Sci Food Agric 86:648-656 (2006).

17 Holm VK, Ndoni S and Risbo J, J Food Sci 71:E40-E44 (2006).

18 Oliveira NS, Gonçalves CM, Coutinho JAP, Ferreira A, Dorgan J and Marrucho IM, Fluid Phase Equilib 250:116-124 (2006).

19 Petersen K, Nielsen PV and Olsen MB, Starch/Staerke 53:356-361 (2001). 
20 Rhim J-W, Mohanty KA, Singh SP and Ng PKW, Ind Eng Chem Res 45:3059-3066 (2006).

21 Solarski S, Ferreira M and Devaux E, Polymer 46:11187-11192 (2005).

22 Shieh Y-T and Liu G-L, J Polym Sci B: Polym Phys 45:466-474 (2007).

23 Sarasua JR, Prud'homme RE, Wisniewski M, Le Borgne A and Spassky N, Macromolecules 31:3895-3905 (1998).

24 Zuza E, Ugartemendia JM, Lopez A, Meaurio E, Lejardi A and Sarasua JR, Polymer 49:4427-4432 (2008).

25 Ohtani Y, Okumura K and Kawaguchi A, J Macromol Sci B: Phys B42:875-888 (2003).

26 Kint DPR, Martinez DE, llarduya A, Sansalvado A, Ferrer J and MunozGuerra S, J Appl Polym Sci 90:3076-3086 (2003).

27 MacDonald RT, McCarthy SP and Gross RA, Macromolecules 29:7356-7361 (1996).

28 Urayama H, Kanamori T and Kimura Y, Macromol Mater Eng 286:705-713 (2001).

29 Auras R, Harte B and Selke S, J Appl Polym Sci 92:1790-1803 (2004).

30 Sanchez-Garcia MD, Gimenez E and Lagaron JM, J Plast Film Sheeting 23:133-148 (2007).

31 Pauly S, in Polymer Handbook, 3rd edition. John Wiley, Chichester, pp. VI 435-449 (1989).

32 Natu AA, Lofgren EA and Jabarin SA, Polym Eng Sci 45:400-409 (2005).

33 Tsuji H, Okino R, Daimon H and Fujie K, J Appl Polym Sci 99:2245-2252 (2006).

34 Sekelik DI, Stepanov EV, Nazarenko S, Schiraldi D, Hiltner A and Baer E, J Macromol Sci B: Phys 37:847-857 (1999).
35 Tsuji H and Ikada Y, Polymer 36:2709-2716 (1995).

36 Liu RYF, Hu YS, Schiraldi DA, Hiltner A and Baer E, J Appl Polym Sci 94:671-677 (2004)

37 Qureshi N, Stepanov EV, Schiraldi D, Hiltner A and Baer E, J Macromol Sci B: Phys 38:1679-1686 (2000).

38 Mano JF, Gomez Ribelles JL, Alves NM and Salmeron Sanchez M, Polymer 46:8258-8265 (2005).

39 Arnoult M, Dargent E and Mano JF, Polymer 48:1012-1019 (2007).

40 Serad GE, Freeman BD, Stewart ME and Hill AJ, Polymer 42:6929-6943 (2001).

41 Hirata Y and Ducruet V, Polym Test 25:690-696 (2006).

42 Qin Y, Rubino M, Auras R and Lim LT, Polym Test 26:1082- 1089 (2007).

43 Favre E, Nguyen QT, Clement R and Neel J, J Membr Sci 117:227-236 (1996).

44 Nielsen TJ and Giacin JR, Packag Technol Sci 7:247-258 (1994).

45 Delpouve N, Saiter A, Mano JF and Dargent E, Polymer 49:3130-3135 (2008).

46 Durning CJ and Russel WB, Polymer 26:131-140 (1985).

47 Ouyang H, Lee W-H, Ouyang W, Shiue ST and Wu TM, Macromolecules 37:7719-7723 (2004).

48 Ouyang H, Lee WH and Shih MC, Macromolecules 35:8428-8432 (2002).

49 Ouyang $\mathrm{H}$ and Shore SH, Polymer 40:5401-5406 (1999).

50 Ouyang $\mathrm{H}$ and Shore SH, J Appl Phys 85:1148-1152 (1999). 